\title{
Changes of gait pattern, muscle activity, and perceived comfort in response to variations of height-elevating insoles in young adults
}

\author{
Se-Yeon Park, Du-Jin Park* \\ Department of Physical Therapy, Kaya University, Gimhae, Korea
}

The purpose of this study was to investigate changes of gait pattern, muscle activity, and perceived comfort in response to variations of height-elevating insoles (HEls) in young adults. The subjects of this study were 30 young adults who voluntarily consented to participate in this experiment after listening to its purpose and method. They were divided into 3 groups who wore HEls height $(0,3$, and $7 \mathrm{~cm})$. Each group consisted of 10 young adults and wore the HEls for $4 \mathrm{hr}$ a day. Electromyographic signals were collected from the tibialis anterior, the gastrocnemius, the hamstring, and the right and the left erector spinae (ES) before and after walking with the HEl. Gait pattern was measured before and after walking with the HEI. Perceived comfort was measured after a subject wore the insoles for $4 \mathrm{hr}$. The activities of ES showed significant differences among the three groups. The activity of the left
ES was significantly different between groups $1(0 \mathrm{~cm})$ and $2(3 \mathrm{~cm})$ and groups 1 and $3(7 \mathrm{~cm})$. The activity of the right ES was significantly different between groups 1 and 3 . The left stride length and the left step length showed significant differences between groups 1 and 3. Perceived comfort was significantly different among the three groups. As the HEls increased, the activities of ES were gradually increased and the left step length and stride were decreased. Using of higher HEls over $4 \mathrm{hr}$ may be occurred excessive activities of the ES, abnormal gait patterns, and perceived discomfort.

Keywords: Height-elevating insoles, Muscle activity, Gait pattern, Perceived comfort

\section{INTRODUCTION}

Walking, an activity that lets the body move without losing stability and balance, is essential for living an independent life. Walking is affected by a wide variety of factors, including heel height, heel size, and the shape of the insole and outsole (Kim, 2008; Lee and Hong, 2005; Lin et al., 2013). Shoes are produced with a focus on activity and functionality for gait, and yet many women tend to wear high-heeled shoes to look more beautiful and attractive. It has been reported that $37 \%$ to $69 \%$ of the total female population may choose to wear high heels on a daily basis (American Podiatric Medical Association, 2003; Frey et al., 1993). However, a number of problems are caused by wearing high heels.
Wearing high heels excessively increases the activity of the muscles around the ankles, such as the soleus, the tibialis anterior (TA), the gastrocnemius (GN), and the peroneus longus (Cronin et al., 2012; Simonsen et al., 2012; Stefanyshyn et al., 2000). These extended muscular activities can contribute to inefficient energy consumption, as well as an increase in the likelihood of fatigue (Ebbeling et al., 1994). In particular, the peroneus longus and the lateral fiber of the GN are more vulnerable to fatigue than those of other muscles (Gefen et al., 2002). Fatigue in these two muscles may decrease the amount of frictional force against the ground, increasing the risk of slips or falls (Hyun et al., 2016).

Wearing the high heels for walking generate force spikes at the initial contact with ground and the force is then transmitted up to the skeleton as a "shock wave" (Voloshin and Loy, 1994), which
${ }^{*}$ Corresponding author: Du-Jin Park (iD https://orcid.org/0000-0002-5658-3343 Department of Physical Therapy, Kaya University, 208 Samgye-ro, Gimhae 50830, Korea

Tel: +82-55-330-1047, Fax: +82-55-344-5285, E-mail: djpark35@kaya.ac.kr Received: January 2, 2018 / Accepted: January 30, 2018
This is an Open Access article distributed under the terms of the Creative Commons Attribution Non-Commercial License (http://creativecommons.org/licenses/by-nc/4.0/) which permits unrestricted non-commercial use, distribution, and reproduction in any medium, provided the original work is properly cited. 
may cause degenerative joint damage and low back pain (LBP) (Kerrigan et al., 1998). As heel height increases, the lumbar flexion angle decreases, resulting in unstable posture and additional compressive forces on the lumbar spine (Lee et al., 2001). These mechanisms can cause LBP by increasing fatigue in the muscles around the lumbar spine (Hyun and Kim, 1997).

To avoid the negative effects caused by wearing high heels, an increasing number of women are wearing shoes equipped with height-elevating insoles (HEIs) rather than high heels, while some men also use HEIs in shoes to appear taller. This trend has attracted consistent interest and research into the usage and effects of HEIs. Stolwijk et al. (2011) investigated changes in plantar pressure depending on the presence or absence of insoles among 204 subjects complaining of foot discomfort; Lin et al. (2013) demonstrated the windlass effect based on insole design; and other studies have established the postural stability or the muscular activities of the lower limbs according to the types and materials of insoles (Hamlyn et al., 2012; Hatton et al., 2009).

Although studies on insoles have been on the increase, few studies have determined changes in bodies according to HEIs heights. Therefore, this study was to investigate changes of gait pattern, muscle activity, and perceived comfort in response to variations of HEIs in young adults.

\section{MATERIALS AND METHODS}

\section{Subjects}

The subjects of this study were 30 healthy adults (21 male and 9 female subjects), who voluntarily participated in this study after being informed of its purpose. Individuals who had undergone foot, ankle, knee, or back surgeries, had experienced waist deformation or pain, wearing HEIs, or had problems with gait patterns were excluded from the experiment. All the subjects were randomly divided into three groups based on the insole heights. Each group consisted of 10 young adults ( 7 male, 3 female subjects). The procedures of this study were approved by the Research Ethics Committee of the Kaya University (approval number: 201701 92).

\section{HEls and shoes}

The HEIs used in this experiment were purchased in the market. Participants were inserted the HEIs (whose heights were 0 $\mathrm{cm}, 3 \mathrm{~cm}$, and $7 \mathrm{~cm}$; Fig. 1) into shoes for this experiment. Because shoe size can affect gait and the muscular activities of the lower limbs (Kim, 2008), all subjects wore shoes that fit their foot size. Shoes with rocker type outsoles were excluded because of their effect on gait (Lin et al., 2013).

\section{Electromyography}

Surface electromyography (EMG) (Free EMG 300, BTS Bioengineering, Garbagnate Milanese, Italy) was used to measure the muscular activities. Surface electrodes were attached to the TA, the $\mathrm{GN}$, and the biceps femoris (BF) of the dominant leg, and to the left and right side of the erector spinae (ES). The EMG signals were sampled with a $1,000 \mathrm{~Hz}$ frequency. The data obtained were computerized with the EMG acquisition software (BTS, BTS Bioengineering S.p.A.. Milano, Italy). The skin was prepared for EMG measurement by cleaning the electrode site with alcohol. Three surface electrodes were placed on the dominant right side over the belly of the TA, GN, and BF in the positions outlined by
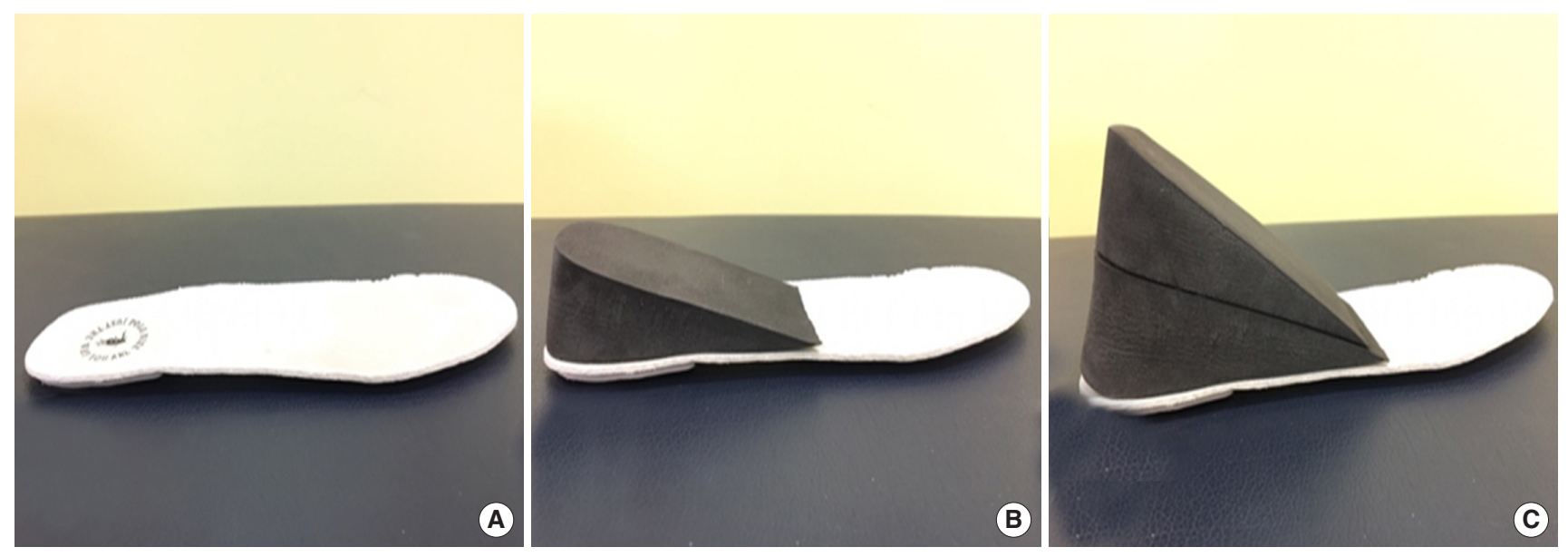

Fig. 1. Height-elevating insoles: $0 \mathrm{~cm}(A), 3 \mathrm{~cm}(B)$, and $7 \mathrm{~cm}(C)$. 
the SENIAM (surface EMG for a noninvasive assessment of muscles) guidelines (Hermens et al., 2000). ES was placed $3 \mathrm{~cm}$ lateral to the L4 spinous process, and another directly above it on the right and left side (Barton et al., 2009). To standardize the muscular activities, reference voluntary isometric contraction was measured, which was set on the basis of the activity of each muscle while a subject walked barefoot for a designated distance.

\section{Gait analysis system}

To analyze the subjects' gait patterns, the GAITRite system (GAITRITE, CIR Systems Inc., Sparta, NJ, USA) was used to measure their step length, stride length, and cadence. When an investigator said, "Please walk as usual," a subject (either barefoot or wearing the HEI-inserted shoes) walked a distance of $2 \mathrm{~m}$ for measurement.

\section{Perceived comfort}

The visual analogue scale (VAS) is a reliable measure for assessing footwear comfort (Mündermann et al., 2002). The VAS has been used to rate footwear comfort in previous studies (Lee and Hong, 2005; Mündermann et al., 2002). The scale ranges from 0 (not comfortable at all) to 10 (the most comfortable condition imaginable). Perceived comfort was measured after a subject wore the insoles for $4 \mathrm{hr}$.

\section{Procedure}

After wearing the shoes with the HEIs for $4 \mathrm{hr}$ for adaptation, the subjects performed controlled activities in a designated place, and then were measured their gait pattern, the muscular activities of the lower limb and the lumbar spine, and perceived comfort. The subjects were asked to walk a distance of $2 \mathrm{~m}$ in their usual manner and then on the gait analysis system. All measurements were conducted three times, and the mean values of the three were analyzed.

\section{Statistical analysis}

One-way analysis of variance was performed to analyze the muscular activities and gait patterns according to the HEIs heights. Tukey multiple comparison analysis was used as a post hoc test. IBM SPSS ver. 18.0 (IBM Co., Armonk, NY, USA) was used for the statistical analyses. The significance level ( $\alpha$ ) was set at 0.05 .

Table 1. General characteristics of participants $(n=30)$

\begin{tabular}{lccccc}
\hline Characteristic & Group 1 $(\mathrm{n}=10)$ & Group 2 $(\mathrm{n}=10)$ & Group 3 $(\mathrm{n}=10)$ & $F$ & $P$-value \\
\hline Age $(\mathrm{yr})$ & $21.20 \pm 1.55$ & $20.80 \pm 0.92$ & $20.40 \pm 0.52$ & 1.36 & 0.27 \\
Height $(\mathrm{cm})$ & $168.70 \pm 9.43$ & $169.10 \pm 7.35$ & $165.70 \pm 10.91$ & 0.40 & 0.68 \\
Weight $(\mathrm{kg})$ & $63.70 \pm 10.45$ & $64.80 \pm 10.82$ & $60.30 \pm 9.26$ & 0.53 & 0.60 \\
BMI $\left(\mathrm{kg} / \mathrm{m}^{2}\right)$ & $22.34 \pm 2.92$ & $22.72 \pm 3.95$ & $22.29 \pm 2.28$ & 0.06 & 0.94 \\
\hline
\end{tabular}

Values are presented as mean \pm standard deviation.

$\mathrm{BMl}$, body mass index.

Table 2. Changes of muscle activity on the variations of height-elevating insoles during gait

\begin{tabular}{lccccc}
\hline Variable & Group $1(0 \mathrm{~cm})$ & Group 2 $(3 \mathrm{~cm})$ & Group 3 $(7 \mathrm{~cm})$ & $F$ & $P$-value \\
\hline TA & $110.90 \pm 33.22$ & $123.51 \pm 28.15$ & $102.20 \pm 22.29$ & 1.44 & 0.26 \\
GN & $116.86 \pm 58.97$ & $142.48 \pm 52.33$ & $106.75 \pm 48.68$ & 1.19 & 0.32 \\
BF & $178.11 \pm 153.72$ & $132.70 \pm 67.33$ & $149.33 \pm 92.21$ & 0.43 & 0.65 \\
Left ES* & $94.29 \pm 20.62$ & $116.20 \pm 22.16$ & $129.40 \pm 15.76$ & 8.10 & 0.00 \\
Right ES* & $99.50 \pm 27.14$ & $112.35 \pm 13.12$ & $134.52 \pm 24.80$ & 6.17 & 0.00
\end{tabular}

Values are presented as mean \pm standard deviation. Unit: \%RVIC.

$T A$, tibialis anterior; $G N$, gastrocnemius; $B F$, biceps femoris; $E S$, erector spinae; RVIC, reference voluntary isometric contraction.

*Significant difference between conditions.

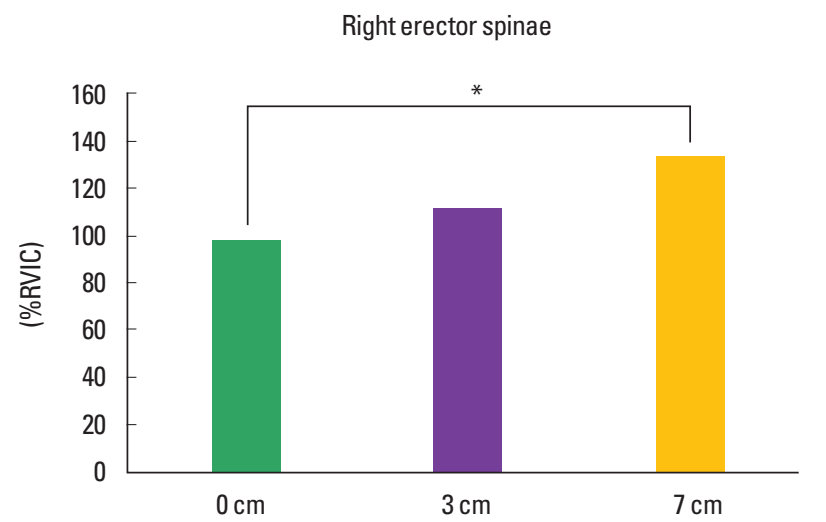

Fig. 2. Activity of erector spinae on the variations of height-elevating insoles during gait. RVIC, reference voluntary isometric contraction. * Significant difference between conditions. 


\section{RESULTS}

No significant differences were found among the three groups in terms of mean age, height, weight, and body mass index (Table 1). The present study was investigated activities of the TA, the GN, the $\mathrm{BF}$, and the right and the left ES before and after walking with the HEIs (Table 2). The activity of the left ES was significantly different between groups $1(0 \mathrm{~cm})$ and $2(3 \mathrm{~cm})$ and groups 1 and $3(7 \mathrm{~cm})$ (Fig. 2). The activity of the right ES was significantly different between groups 1 and 3 (Fig. 2).

In terms of stride length (the right and the left), step length (the

Table 3. Differences of gait pattern between barefoot and wearing height-elevating insoles

\begin{tabular}{lccccc}
\hline Variable & Group 1 $(0 \mathrm{~cm})$ & Group 2 $(3 \mathrm{~cm})$ & Group 3 $(7 \mathrm{~cm})$ & $F$ & $P$-value \\
\hline Left SL $(\mathrm{cm})^{*}$ & $5.17 \pm 4.16$ & $3.43 \pm 4.38$ & $-0.30 \pm 4.17$ & 4.36 & 0.02 \\
Right SL $(\mathrm{cm})$ & $4.94 \pm 4.24$ & $3.21 \pm 3.55$ & $1.37 \pm 5.28$ & 1.64 & 0.21 \\
Left StL $(\mathrm{cm})^{*}$ & $3.92 \pm 5.26$ & $0.98 \pm 5.26$ & $-4.18 \pm 6.50$ & 4.05 & 0.03 \\
Right StL $(\mathrm{cm})$ & $8.47 \pm 8.32$ & $6.23 \pm 7.81$ & $1.00 \pm 8.59$ & 2.17 & 0.13 \\
Cadence $(\mathrm{m} / \mathrm{sec})$ & $-4.36 \pm 14.04$ & $-4.50 \pm 2.60$ & $-4.68 \pm 6.27$ & 0.01 & 0.99 \\
\hline
\end{tabular}

Values are presented as mean \pm standard deviation.

SL, stride length; StL, step length.

${ }^{*}$ Significant difference between conditions.
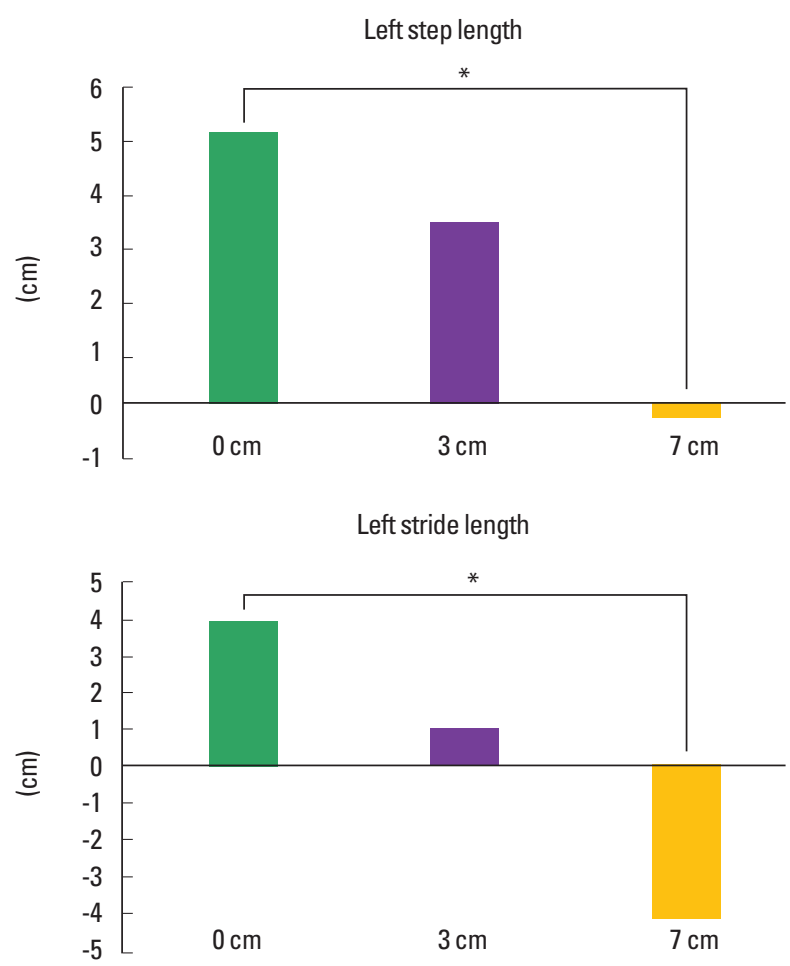

Fig. 3. Differences of gait pattern between barefoot and wearing height-elevating insoles. *Significant difference between conditions. right and the left), and cadence during walking before and after wearing the HEI-inserted shoes, the left stride length and the left step length showed significant differences between groups 1 and 3 (Table 3, Fig. 3). The VAS scores were significantly different among all three groups (Table 4, Fig. 4).

\section{DISCUSSION}

In this study, the activities of the left and right ES significantly increased during walking with higher HEIs. Other studies have found that the activities of ES generally increase as shoe heels become higher (Barton et al., 2009; Lee et al., 2001). The activities of the ES increase more as cadence increases more, or as high heels become higher regardless of cadence (Nam et al., 2014). It has been reported that wearing heels of $6 \mathrm{~cm}$ resulted in significantly more fatigue in the ES than lower heels. These results may mean increasing the likelihood of LBP. In the current study, the activities of the ES also increased when the $7 \mathrm{~cm}$ HEIs were worn. If young adults wear 7-cm HEIs for a long time, this may cause LBP because prolonged ES activity can increase the muscle fatigue. Some previous studies have suggested that the force spike of high heels in initial contact with the ground is likely to cause LBP (Kerrigan et al., 1998; Voloshin and Loy, 1994). However, this hypothesis could not be verified in this study because the

Table 4. Changes of perceived comfort on the variations of height-elevating insoles

\begin{tabular}{cccccc} 
& Group $1(0 \mathrm{~cm})$ & Group $2(3 \mathrm{~cm})$ & Group $3(7 \mathrm{~cm})$ & $F$ & $P$-value \\
\hline VAS* $^{*}$ & $10.0 \pm 0.00$ & $7.70 \pm 1.42$ & $5.90 \pm 1.79$ & 24.26 & 0.00 \\
\hline
\end{tabular}

Values are presented as mean \pm standard deviation.

VAS, visual analogue score.

*Significant difference between conditions

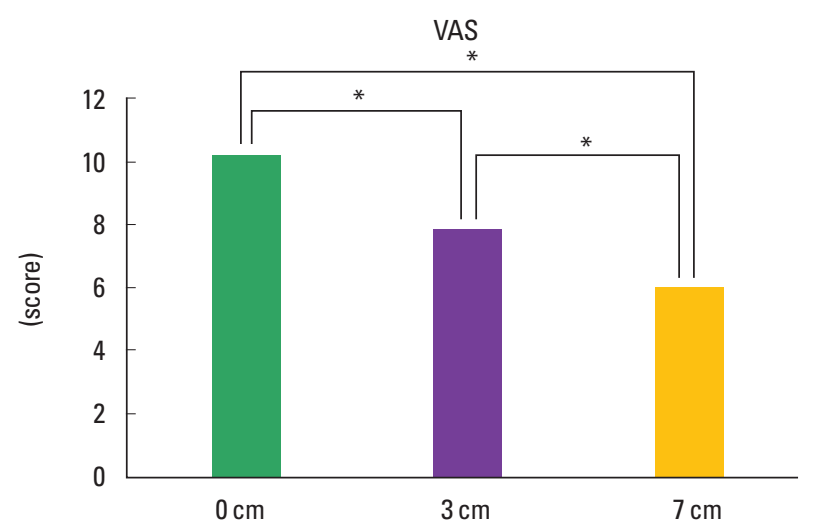

Fig. 4. Perceived comfort after wearing height-elevating insoles. VAS, visual analogue scale. *Significant difference between conditions. 
subjects wore insoles whose contact areas were larger than those of high heels and we did not measure their force in initial contact.

The activities of the lower limb muscles in this study decreased more as the HEIs became higher, without significant differences. This result was not consistent with that of previous studies on high heels (Cronin et al., 2012; Simonsen et al., 2012; Stefanyshyn et al., 2000), an inconsistency that could be caused by differences in the research subjects and methods. Although the previous studies measured the muscular activities of those who had worn high heels for a long time, in this study we measured the activities after four hours of wearing the HEIs. Because the subjects in this study had not experienced HEIs before, the four hours of wearing the HEIs may have increased fatigue in the lower limbs and the muscular activities decreased, unlike the previous studies. As increased fatigue in leg muscles, the demand for posture control of the lumbopelvic region may be increased by the forward and upward movement of the body's center of mass (COM) (Lee et al., 2001; Park et al., 2013), and then it may be increased the activities of the ES. Increased lordosis due to excessive activities of the ES may accompany changes in the muscle-tendon properties, inducing potential increases in muscular fatigue and back pain (Cronin, 2014). In addition, long-term use of high insoles may induce excessive energy consumption and circulatory disturbances, leading to chronic LBP.

Yang et al. (2013) reported that higher insoles decreased the step length of the left foot significantly, while Park et al. (2013) argued that stride length was significantly decreased more by wearing high heels than by flat shoes. In the current study as well, as the HEIs became higher, not only the left step length but also the left stride length decreased significantly. Midstance is when the body's COM is highest, with the GN and the soleus activated (Neumann, 2016). In this study, when the HEIs were higher, the muscular activities of the lower limbs were lower, leading to an unstable mid-stance, which can increase activities of the ES due to the fluctuation of the body's COM. This process can cause significant changes in the step length and stride length of the left leg as the nondominant side during the midstance of the dominant leg; it can similarly affect the step length and stride length of the right leg as the dominant side during the midstance of the nondominant leg, though no statistical difference was shown in the current study. A previous study reported that no significant differences were observed in the step length or stride length according to insoles heights (Lee, 2014). This result that could be caused by the fact that the insoles used in Lee's study were not greatly different in height $(0,2,3$, and $5 \mathrm{~cm})$. Other previous studies (Park et al.,
2013; Yang et al., 2013), as well as this study, used the maximum height available for high heels or insoles over $7 \mathrm{~cm}$.

The VAS is a reliable tool for evaluating footwear comfort, with which we measured the perceived comfort of the subjects according to insole heights. The higher the HEIs, the less the comfort. If discomfort due to insoles persists, it may lead to deformed feet, an increase in the peak pressure on the forefoot, a shortening of the Achilles tendon, and plantar fasciitis (Cronin, 2014; Ebbeling et al., 1994; Lee and Hong, 2005). Further studies are needed to determine any further effects of shoe inserts to prevent these problems.

As the HEIs increased, the activities of ES were gradually increased and the left step length and stride were decreased. Using of higher HEIs over $4 \mathrm{hr}$ may be occurred excessive activities of the ES, abnormal gait patterns, and perceived discomfort.

\section{CONFLICT OF INTEREST}

No potential conflict of interest relevant to this article was reported.

\section{ACKNOWLEDGMENTS}

This research was supported by the National Research Foundation of Korea (NRF) grant funded by Ministry of Science and ICT (No. 2017R1C1B5074795).

\section{REFERENCES}

American Podiatric Medical Association. High Heels Survey. Bethesda (MD): American Podiatric Medical Association; 2003.

Barton CJ, Coyle JA, Tinley P. The effect of heel lifts on trunk muscle activation during gait: a study of young healthy females. J Electromyogr Kinesiol 2009;19:598-606.

Cronin NJ. The effects of high heeled shoes on female gait: a review. J Electromyogr Kinesiol 2014;24:258-263.

Cronin NJ, Barrett RS, Carty CP. Long-term use of high-heeled shoes alters the neuromechanics of human walking. J Appl Physiol (1985) 2012;112:1054-1058.

Ebbeling CJ, Hamill J, Crussemeyer JA. Lower extremity mechanics and energy cost of walking in high-heeled shoes. J Orthop Sports Phys Ther 1994;19:190-196.

Frey C, Thompson F, Smith J, Sanders M, Horstman H. American Orthopaedic Foot and Ankle Society women's shoe survey. Foot Ankle 1993;14:78-81. 
Gefen A, Megido-Ravid M, Itzchak Y, Arcan M. Analysis of muscular fatigue and foot stability during high-heeled gait. Gait Posture 2002;15: 56-63.

Hamlyn C, Docherty CL, Klossner J. Orthotic intervention and postural stability in participants with functional ankle instability after an accommodation period. J Athl Train 2012;47:130-135.

Hatton AL, Dixon J, Martin D, Rome K. The effect of textured surfaces on postural stability and lower limb muscle activity. J Electromyogr Kinesiol 2009;19:957-964.

Hermens HJ, Freriks B, Disselhorst-Klug C, Rau G. Development of recommendations for SEMG sensors and sensor placement procedures. J Electromyogr Kinesiol 2000;10:361-374.

Hyun SD, Kim JY. The effects of high heel on back muscle fatigue. J Ergon Soc Korea 1997;16:37-48.

Hyun SH, Kim YP, Ryew CC. Effect on the parameters of the high-heel shoe and transfer time of ground reaction force during level walking. J Exerc Rehabil 2016;12:451-455.

Kerrigan DC, Todd MK, Riley PO. Knee osteoarthritis and high-heeled shoes. Lancet 1998;351:1399-1401.

Kim TH. Effect of shoe size on foot pressure, ground reaction force, and fatigue during walking and running. Physic Ther Korea 2008;15:1-11.

Lee CM, Jeong EH, Freivalds A. Biomechanical effects of wearing highheeled shoes. Int J Ind Ergon 2001;28:321-326.

Lee $\mathrm{YH}$, Hong WH. Effects of shoe inserts and heel height on foot pressure, impact force, and perceived comfort during walking. Appl Ergon 2005;36:355-362.

Lee YJ. The effect of the shoes insole height on the gait in male college student. Korean J Sport 2014;12:437-445.

Lin SC, Chen CP, Tang SF, Wong AM, Hsieh JH, Chen WP. Changes in windlass effect in response to different shoe and insole designs during walking. Gait Posture 2013;37:235-241.

Mündermann A, Nigg BM, Stefanyshyn DJ, Humble RN. Development of a reliable method to assess footwear comfort during running. Gait Posture 2002;16:38-45.

Nam SJ, Kim MJ, Yim SJ, Oh DW, Park HJ, Kim CY. Influence of walking speed on electromyographic activity of the rectus abdominis and erector spinae during high-heeled walking. J Back Musculoskelet Rehabil 2014;27:355-360.

Neumann DA. Kinesiology of the musculoskeletal system: foundations for rehabilitation. 3rd ed. St. Louis (MO): Mosby; 2016.

Park S. Lee M, Park J. The relationship among stride parameters, joint angles, and trajectories of the body parts during high-heeled walking of woman. J Ergon Soc Korea 2013;32:245-252.

Simonsen EB, Svendsen MB, Nørreslet A, Baldvinsson HK, Heilskov-Hansen T, Larsen PK, Alkjær T, Henriksen M. Walking on high heels changes muscle activity and the dynamics of human walking significantly. J Appl Biomech 2012;28:20-28.

Stefanyshyn DJ, Nigg BM, Fisher V, O'Flynn B, Liu W. The influence of high heeled shoes on kinematics, kinetics, and muscle EMG of normal female gait. J Appl Biomech 2000;16:309-319.

Stolwijk NM, Louwerens JW, Nienhuis B, Duysens J, Keijsers NL. Plantar pressure with and without custom insoles in patients with common foot complaints. Foot Ankle Int 2011;32:57-65.

Voloshin AS, Loy DJ. Biomechanical evaluation and management of the shock waves resulting from the high-heel gait: I - temporal domain study. Gait Posture 1994;2:117-122.

Yang HS, Yoo YD, Jeong CJ, Kim JH, Kim SH, Kim WJ, Kim KN, Im SR, Wi HG, Wang SJ. The effects of the height increase elevator shoes insole on the gait and balance in adult male. J Korean Soc Sport Physic Ther 2013;9:1-9. 